\title{
OPEN The relationship between serum 25-hydroxyvitamin D levels and the severity of COVID-19 disease and its mortality
}

\author{
Maryam Vasheghani ${ }^{1}$, Nasrin Jannati ${ }^{2}$, Parvaneh Baghaei ${ }^{3}$, Mitra Rezaei ${ }^{4 凶}$, \\ Roqayeh Aliyari ${ }^{1,5} \&$ Majid Marjani ${ }^{6}$
}

Supplemental vitamin $\mathrm{D}$ can reduce the risk and mortality of viral pneumonia. The relationship between 25 hydroxyvitamin D [25(OH)D] levels and the severity and mortality of Coronavirus disease 2019 (COVID-19) was evaluated. In this cross-sectional study, the admitted patients with COVID-19 were categorized as mild, moderate, severe, and critical based on clinical and radiologic characteristics. Calcium, phosphorus, albumin, creatinine, and serum 25(OH)D were measured and their correlation with the severity of disease and mortality were analyzed. During 2 months, 508 patients (442 patients in general wards and 66 patients in the intensive care unit (ICU)) were included. The participants were $56 \pm 17$ years old ( $52 \%$ male, $37 \%$ with comorbidity). Concerning severity, $13 \%$, $42 \%, 36 \%$, and $9 \%$ had mild, moderate, severe, and critical diseases, respectively. The mortality rate was $\mathbf{1 0 . 8 \%}$. Admission to ICU, severity of disease and mortality decreased significantly across quartiles of 25(OH)D. According to multivariate logistic regression analysis, disease mortality had a positive correlation with age and had a negative correlation with the serum level of $25(\mathrm{OH}) \mathrm{D}$, calcium, and albumin. In hospitalized patients with COVID-19, low 25(OH)D was associated with severe disease and increased ICU admission and mortality rate.

In late 2019, a new coronavirus was identified as a cause of a cluster of pneumonia cases in China which is named COVID-19 disease ${ }^{1}$. Currently, COVID-19 is pandemic ${ }^{2}$. In Iran, 612,772 people as the definitive cases of COVID-19 have been reported by November 10, 2020, and 34,864 people have died ${ }^{3}$. Manifestations of the COVID-19 range from asymptomatic carriers to acute respiratory failure and death ${ }^{4}$. Complications include acute respiratory failure, cytokine release syndrome, increased coagulation factors, and multi-organ damage which are associated with poor prognosis ${ }^{5,6}$. The overall mortality rate until November 18,2020 , is about $2.4 \%$ $(1,333,742 \text { deaths between } 55,326,907 \text { patients })^{7}$. Old age, cardiovascular disease, diabetes, high blood pressure, chronic lung disease, cancer, chronic kidney disease, people with defective or suppressed immune systems, obesity, and chronic liver disease have been identified as risk factors for severe disease or mortality ${ }^{4,6,8,9}$. There is currently no specific treatment against COVID-19 disease ${ }^{10}$. Currently, the most important way to deal with this disease is prevention and control of the conditions that are considered as a risk factor for the more severe course, and complications.

There is evidence from influenza A and severe acute respiratory syndrome (SARS) epidemics suggesting a role for vitamin $\mathrm{D}$ in these diseases ${ }^{11}$. Previous studies have suggested an association between vitamin $\mathrm{D}$ deficiency and an increased chance of developing bacterial and/or viral pneumonia due to viruses such as SARS, MERS, and Influenza A. COVID-19 disease is more prevalent and severe in winter and is more common in people who

${ }^{1}$ Chronic Respiratory Diseases Research Center, National Research Institute of Tuberculosis and Lung Diseases (NRITLD), Shahid Beheshti University of Medical Sciences, Tehran, Iran. ${ }^{2}$ Internal Medicine Department, School of Medicine, Shahid Beheshti University of Medical Sciences, Tehran, Iran. ${ }^{3}$ Clinical Tuberculosis and Epidemiology Research Center, National Research Institute of Tuberculosis and Lung Disease (NRITLD), Shahid Beheshti University of Medical Sciences, Tehran, Iran. ${ }^{4}$ Virology Research Center, National Research Institute of Tuberculosis and Lung Diseases, Masih Daneshvari Hospital, Shahid Beheshti University of Medical Sciences, Darabad, Niavaran, 196944413 Tehran, Iran. ${ }^{5}$ Ophthalmic Epidemiology Research Center, Shahroud University of Medical Sciences, Shahroud, Iran. ${ }^{6}$ Clinical Tuberculosis and Epidemiology Research Center, National Research Institute of Tuberculosis and Lung Diseases (NRITLD), Masih Daneshvari Hospital, Shahid Beheshti University of Medical Sciences, Tehran, Iran. ${ }^{\square}$ email: dr_mrezaie@yahoo.com 
are more likely to be deficient in vitamin $\mathrm{D}$, such as people with obesity and diabetes mellitus, and people who live in higher latitudes ${ }^{12,13}$.

About one-half of Iranian people have vitamin D deficiency ( 25 Hydroxyvitamin $\mathrm{D}<20 \mathrm{ng} / \mathrm{dl}$ ) and the burden of COVID-19 is catastrophically rising in Iran with a mortality rate of about $6 \%{ }^{14}$. So, this study investigates the relationship between 25 Hydroxyvitamin D [25(OH)D] levels and the severity and mortality of COVID-19 to plan for improving patients care and reducing morbidity and mortality by appropriate treatment protocols or even planning for primary prevention in the next studies.

\section{Material and methods}

This cross-sectional study was at Masih Daneshvari Hospital (tertiary center for lung disease and tuberculosis and nowadays, COVID-19), Tehran, Iran. Sampling was done by a simple sampling technique of available cases. Therefore, all patients who were hospitalized from April 1, 2020 to June 31, 2020, due to COVID-19, and their serum 25(OH)D levels were checked were included in the study according to the inclusion and exclusion criteria. Patients with COVID-19 who were hospitalized for at least $24 \mathrm{~h}$ were recruited and Cases with an uncertain diagnosis of COVID-19, pregnant women, and those without measurement of serum vitamin D levels were excluded. Informed consent is obtained for participation from participant and their medical history and clinical examination were obtained and recorded in the questionnaire. Patient height and weight were measured with a Seca stadiometer and digital scale. Diagnosis of COVID-19 was made based on reverse transcriptase-polymerase chain reaction (RT-PCR) assay for SARS-CoV-2 from nasopharyngeal or oropharyngeal sampling or a set of symptoms and chest CT scan findings consistent with viral infections by an infectious disease specialist. The RT-PCR test result for SARS-COV-2 is reported as positive or negative. The patients were categorized based on disease severity as mild, moderate, severe, and critical based on clinical symptoms, $\mathrm{O}_{2}$ saturation, and chest imaging (see definition part). Three milliliters of blood were taken from any patient for biochemical tests and a serum level of 25(OH)D. Measurement of calcium, phosphorus, albumin, creatinine was performed by auto analyzer due photometric method (diagnostic kit of Pars Azmoon Company, Tehran, Iran), and serum level of 25(OH)D was measured by chemiluminescent immunoassay (CLIA) (Atellica IM Vitamin D Total Assay, Siemens Company kit, Munich, Germany). The kit used to measure 25 hydroxyvitamin D in this study is standardized according to Vitamin D Standardization-Certification Program (VDSCP). The assay range of this kit is $4.2-150 \mathrm{ng} / \mathrm{ml}$ with the limit of quantitation of $3 \mathrm{ng} / \mathrm{ml}$ and calibration interval every 28 days. This kit has a $1 \%$ cross-reactivity to 3 -epi. The results of total CV and mean bias in different levels of $25(\mathrm{OH}) \mathrm{D}$ are less than $5 \%{ }^{15}$. References value in our laboratory are as definition of vitamin D status (see below).

The clinical and paraclinical parameters related to the severity of the disease were recorded in standard hospital forms for all patients based on the medical history and physical examination by physicians who work in emergency and general wards or ICU. The results of chest imaging have been reported by the radiologists according to the Fleischner Society criteria for interpreting chest CT scan findings consistent with the diagnosis of viral pneumonia (including COVID-19 disease) ${ }^{16}$. The outcome of the disease was classified as partial recovery, complete recovery, and death during hospitalization. Serum levels of $25(\mathrm{OH}) \mathrm{D}$ were not available at the time of recording clinical information such as disease severity and mortality. So, the disease severity and mortality were done blinded to lab data.

Definitions. Vitamin D status has categorized as below ${ }^{17-20}$ :

Severe vitamin D deficiency: $25(\mathrm{OH}) \mathrm{D}<10 \mathrm{ng} / \mathrm{ml}$.

Moderate vitamin D deficiency: $25(\mathrm{OH}) \mathrm{D}=10-20 \mathrm{ng} / \mathrm{ml}$.

Mild vitamin D deficiency: $25(\mathrm{OH}) \mathrm{D}=21-30 \mathrm{ng} / \mathrm{ml}$.

Vitamin D adequacy: 25(OH)D $=30-100 \mathrm{ng} / \mathrm{ml}$.

Upper level Vitamin D: 25(OH)D > 100-149 $\mathrm{ng} / \mathrm{ml}$.

Vitamin D quartiles. $\quad 25(\mathrm{OH}) \mathrm{D}$ is divided in quartiles. The cut-off points for $25(\mathrm{OH}) \mathrm{D}$ quartiles $(25,50$, and 75 ) are 14,24 , and $37 \mathrm{ng} / \mathrm{ml}$, respectively.

Vitamin D supplementation. Those who received at least 50,000 units of vitamin D in the past month.

Definitive COVID-19 infection. A patient who has at least one PCR test of his or her respiratory sampling positive for the SARS-CoV-2 virus ${ }^{21}$.

The severity of COVID-19 disease. According to the guidelines of the World Health Organization based on the patient's respiratory status at the time of blood sampling, oxygen in the blood at rest and room air, as well as the respiratory rate were divided into four groups: mild, moderate, severe, and $\mathrm{Critical}^{21}$.

Mild pulmonary involvement:

$\mathrm{O}_{2}$ sat at rest $>93 \%$ in room air and respiratory rate $<30$ and normal lung CT.

Moderate pulmonary involvement:

$\mathrm{O}_{2}$ sat at rest $>93 \%$ in room air and respiratory rate $<30$ and involvement in lung CT. 
Severe pulmonary involvement:

$\mathrm{O}_{2}$ sat at rest $<93 \%$ in room air and/or respiratory rate $>30$ and involvement in lung CT.

Critical pulmonary involvement:

I. Need nasal high flow oxygen therapy.

II. Requires intubation and mechanical ventilation.

III. Acute respiratory distress syndrome (ARDS).

Outcome COVID-19 disease. Partial recovery. Need $\mathrm{O}_{2}$ therapy after discharge from the hospital or unable to live at home alone and needs to help with self-care.

Body mass index (BMI). $\quad$ BMI is obtained by dividing weight in kilograms by height squared in meters ${ }^{22}$.

Statistical analysis. All data were entered into SPSS statistical software (IBM Corp. Released 2013. IBM SPSS Statistics for Windows, Version 22.0. Armonk, NY: IBM Corp.) and analyzed. A P-value less than 0.05 was considered statistically significant. Participants were divided into four groups based on the severity of the disease. For some quantitative variables when did not have a normal distribution in the Kolmogorov-Smirnov normality test, the nonparametric tests have been applied. The relation between these variables with disease outcome (complete recovery or partial recovery and death) was compared by Mann-Whitney Test. Chi-Square tests were used to examine the relationship between disease severity and outcome with disciplinary variables such as gender, comorbidities (diabetes, hypertension and ischemic heart disease, immune suppression disease), or history of glucocorticoid or vitamin D supplement usage.

The serum level of $25(\mathrm{OH}) \mathrm{D}$ is divided into quartiles. The relationships of demographic (age, sex) and medical parameters (admision ward and history of DM, IHD, glucocorticoid use, and vitamin D supplement use) of participants, and disease severity and outcome were compared across quartiles of serum 25(OH)D by analysis of covariance, then the Bonferroni post hoc test was done for specific between-group comparisons.

The association between the serum level of $25(\mathrm{OH}) \mathrm{D}$ as a continuous independent variable and in-hospital mortality were determined using binary logistic regression analysis with adjustment for age, sex, BMI, creatinine, calcium, phosphor, albumin, and history of comorbidities (diabetes mellitus, hypertension, and ischemic heart disease). Data are presented as $\beta$ regression, $95 \%$ confidence interval, and odds ratio (OR) of $25(\mathrm{OH}) \mathrm{D}$ for in-hospital mortality vs. recovery.

Ethics approval and consent to participate. In this research, the ethical principles of research have been observed according to the Helsinki Convention. Written informed consent has been obtained for participation from the participant. All data is confidential. The data will be printed in groups without mentioning the names and personal details of the participants. The proposal of this plan was approved by the Ethics Committee in Biomedical Research of the National Research Institute of Tuberculosis and Lung Diseases-Shahid Beheshti University of Medical Sciences with the approval ID: IR.SBMU.NRITLD.REC.1399.132 on May 26, 2020.

Consent for publication. The authors wish to submit an original research article entitled "The relationship between serum 25-hydroxyvitamin D levels and the severity of COVID-19 disease and its mortality" for consideration by Scientific Reports. We confirm that this work is original and has not been published elsewhere, nor is it currently under consideration for publication elsewhere.

\section{Results}

During the study period, 556 patients were admitted, 482 cases in general wards, and 72 individuals in Intensive Care Units (ICU). Due to the death during the first $24 \mathrm{~h}$ of admission, failure to send the patient's blood sample for the requested tests, or failure to perform a $25(\mathrm{OH}) \mathrm{D}$ test and exclusion criteria, only available data related to 442 patients admitted to the general wards and 66 patients admitted to the ICU were analyzed. The mean age of participants was $56 \pm 17$ years (range from 14 to 95 years) and $52 \%$ were male. According to the past medical history from the patients, 190 (37.4\%) of patients had comorbidities (diabetes mellitus, ischemic heart diseases, hypertension, etc.). Concerning disease severity, $13 \%, 42 \%, 36 \%$, and $9 \%$ had mild, moderate, severe, and critical diseases, respectively. In this study, $44 \%$ of patients needed advanced respiratory care, and $13 \%$ needed to be admitted to the ICU. The in-hospital mortality rate was $10.8 \%$. People with critical illness had higher age, lower serum levels of $25(\mathrm{OH}) \mathrm{D}$, calcium, albumin, and fewer vitamin $\mathrm{D}$ supplements usage, higher mortality rather than those with mild disease. The relationship between demographic and medical parameters with the severity of COVID-19 disease is listed in Table 1. Based on the Bonferroni post hoc test, the mean age among patients with mild disease was significantly different from the mean age of patients in other groups (P-values $<0.003$ ). The mean level of $25(\mathrm{OH}) \mathrm{D}$ among patients with the critical status was significantly different from other groups (P-values $<0.04)$. The mean phosphorus levels in patients with mild and moderate status significant differences $(\mathrm{P}$-value $=0.04)$ were observed. There was a significant difference between the mean calcium in critical disease with moderate disease ( $\mathrm{P}$-values $<0.0001)$ and mild disease ( $\mathrm{P}$-values $<0.0001)$. Also, the mean calcium levels in patients with severe disease and patients with mild disease $(\mathrm{P}$-value $=0.02)$ were different. 


\begin{tabular}{|c|c|c|c|c|c|c|}
\hline \multirow[b]{2}{*}{ Variables } & \multirow[b]{2}{*}{ Total $(n=508)$} & \multicolumn{4}{|c|}{ Disease severity } & \multirow[b]{2}{*}{ P-value } \\
\hline & & Mild $(\mathbf{n}=68)$ & Moderate $(n=217)$ & Severe $(n=157)$ & Critical $(n=66)$ & \\
\hline Age $^{\mathrm{a}}($ year $)$ & $56 \pm 17$ & $48 \pm 17$ & $56 \pm 17$ & $56 \pm 16$ & $63 \pm 15$ & 0.001 \\
\hline Sex; male, n (\%) & $264(52)$ & $42(62)$ & $103(47)$ & $81(52)$ & $38(58)$ & 0.15 \\
\hline $\mathrm{BMI}^{\mathrm{a}}\left(\mathrm{kg} / \mathrm{m}^{2}\right)$ & $27 \pm 5$ & $27 \pm 4$ & $27 \pm 5$ & $27 \pm 5$ & $27 \pm 5$ & 0.95 \\
\hline \multicolumn{7}{|l|}{ Medical history; yes, n (\%) } \\
\hline $\mathrm{DM}$ & $116(23)$ & $13(19)$ & $43(20)$ & $41(26)$ & $19(29)$ & 0.27 \\
\hline HTN & $35(7)$ & $1(1)$ & $16(7)$ & $13(8)$ & $5(8)$ & 0.29 \\
\hline IHD & $72(14)$ & $7(10)$ & $30(14)$ & $23(15)$ & $12(18)$ & 0.62 \\
\hline Immune system suppression & $31(6)$ & $2(3)$ & $11(5)$ & $15(8)$ & $3(6)$ & 0.38 \\
\hline Glucocorticoid use & $27(5.3)$ & $2(3)$ & $15(7)$ & $8(5)$ & $2(3)$ & 0.48 \\
\hline Vitamin D supplement use & $88(17)$ & $14(21)$ & $42(19)$ & $31(20)$ & $1(1)$ & 0.004 \\
\hline \multicolumn{6}{|c|}{ COVID-19 disease outcome, $\mathbf{n}(\%)$} & 0.001 \\
\hline Death & $55(10.8)$ & $0(0)$ & $3(1)$ & $31(17)$ & $21(46)$ & \\
\hline Partial recovery & $253(50)$ & $12(18)$ & $111(52)$ & $111(62)$ & $19(41)$ & \\
\hline Complete recovery & $200(39)$ & $55(82)$ & $101(47)$ & $38(21)$ & $6(13)$ & \\
\hline $25 \mathrm{OH}$ vitamin $\mathrm{D}^{\mathrm{a}}(\mathrm{ng} / \mathrm{ml})$ & $28.6 \pm 21.6$ & $31.8 \pm 25.7$ & $30.4 \pm 22.4$ & $28.2 \pm 20.8$ & $20.4 \pm 16.3$ & 0.001 \\
\hline Creatinine $^{\mathrm{a}}(\mathrm{mg} / \mathrm{dl})$ & $1.4 \pm 1.2$ & $1.5 \pm 1.9$ & $1.3 \pm 1.0$ & $1.4 \pm 1.1$ & $1.6 \pm 1.0$ & 0.28 \\
\hline Calcium $^{\mathrm{a}}$ (mg/dl) & $8.8 \pm 0.7$ & $9.0 \pm 0.8$ & $8.8 \pm 0.6$ & $8.7 \pm 0.6$ & $8.5 \pm 0.8$ & 0.001 \\
\hline Phosphor $^{\mathrm{a}}(\mathrm{mg} / \mathrm{dl})$ & $3.3 \pm 1.06$ & $3.6 \pm 0.8$ & $3.2 \pm 0.9$ & $3.1 \pm 0.8$ & $3.4 \pm 1.8$ & 0.02 \\
\hline $\operatorname{Albumin}^{\mathrm{a}}(\mathrm{g} / \mathrm{dl})$ & $3.4 \pm 0.6$ & $3.9 \pm 0.5$ & $3.5 \pm 0.5$ & $3.5 \pm 0.8$ & $3.0 \pm 0.4$ & 0.001 \\
\hline
\end{tabular}

Table 1. Relationship between demographic and medical parameters with the severity of COVID-19 disease. $D M$ diabetes mellitus, $H T N$ hypertension, $I H D$ ischemic heart disease, $B M I$ body mass index. ${ }^{a}$ Mean \pm SD.

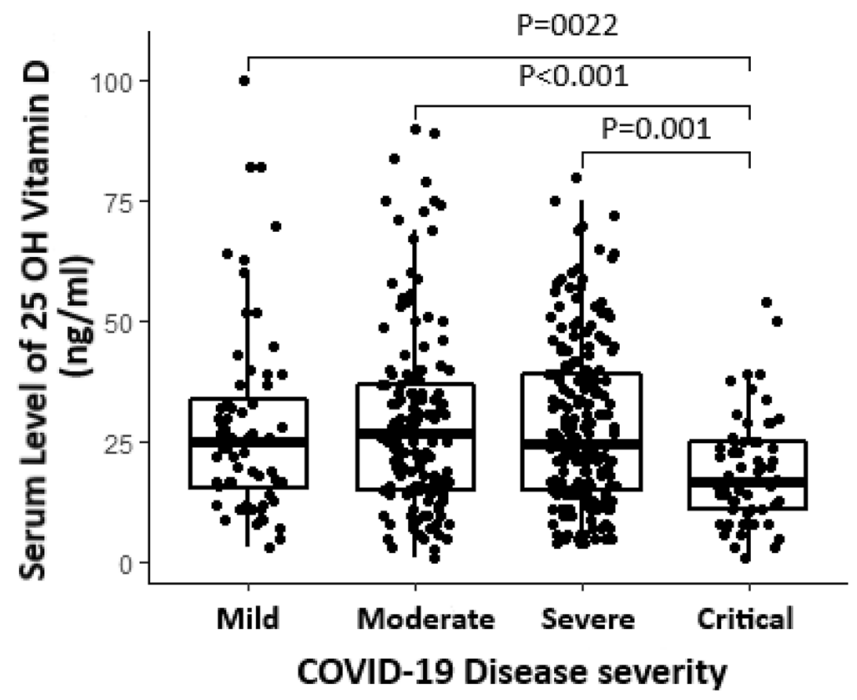

Figure 1. Comparative diagram of median and interquartile of serum 25 hydroxyvitamin $\mathrm{D}$ level in different intensities of COVID-19 disease.

Figure 1 is a box plot showing median and interquartile range of 25(OH)D and different levels of disease severity. The comparisons between median serum vitamin $\mathrm{D}$ levels based on severity of disease examined by Mann-Whitney test due to the abnormal distribution of serum 25(OH)D levels. The P-values in Fig. 1 represent the statistically differences between groups. Vitamin D deficiency $(25(\mathrm{OH}) \mathrm{D}<30 \mathrm{ng} / \mathrm{ml})$ was more common in women than men $(69 \%$ vs. $56 \%, \mathrm{P}=0.003)$ and patients under ICU care than patients admitted in other wards $(80 \%$ vs. $61 \%, \mathrm{P}=0.01)$. The prevalence of vitamin $\mathrm{D}$ deficiency and critical illness was lower in people taking vitamin $\mathrm{D}$ supplements $(\mathrm{P}=0.001$ for both). The prevalence of vitamin $\mathrm{D}$ deficiency was not different between patients with a history of comorbidities and those without it.

Table 2 summarized the patient's demographic and medical characteristics based on the outcome. The mortality is directly related to the patient's age and the severity of the disease. The mortality of people older than 


\begin{tabular}{|c|c|c|c|c|}
\hline \multirow[b]{2}{*}{ Variables } & \multicolumn{3}{|c|}{ COVID-19 disease outcome } & \multirow[b]{2}{*}{ P-value } \\
\hline & $\begin{array}{l}\text { Death } \\
\mathrm{n}=55\end{array}$ & $\begin{array}{l}\text { Partial recovery } \\
n=253\end{array}$ & $\begin{array}{l}\text { Complete recovery } \\
n=200\end{array}$ & \\
\hline Age $^{\mathrm{a}}$ & $65 \pm 15$ & $58 \pm 17$ & $51 \pm 16$ & 0.001 \\
\hline Sex; male, n (\%) & $25(45.5)$ & $118(46.6)$ & $101(51)$ & 0.66 \\
\hline $\mathrm{BMI}^{\mathrm{a}}\left(\mathrm{kg} / \mathrm{m}^{2}\right)$ & $26 \pm 5$ & $27 \pm 5$ & $27 \pm 5$ & 0.61 \\
\hline \multicolumn{5}{|l|}{ PMH; yes, n (\%) } \\
\hline $\mathrm{DM}$ & $13(23.6)$ & $64(25.3)$ & $39(20)$ & 0.34 \\
\hline HTN & $4(7.3)$ & $22(8.7)$ & $9(5)$ & 0.21 \\
\hline IHD & $8(14)$ & $44(17)$ & $20(10)$ & 0.08 \\
\hline Immune system suppression & $6(10.9)$ & $16(6.3)$ & $9(5)$ & 0.21 \\
\hline Glucocorticoid use & $4(7.3)$ & $12(4.7)$ & $11(6)$ & 0.74 \\
\hline Vitamin D supplement use & $7(12.7)$ & $47(18.6)$ & $34(17)$ & 0.58 \\
\hline \multicolumn{4}{|c|}{ COVID-19 disease severity, n (\%) } & 0.001 \\
\hline Mild & $0(0)$ & $12(5)$ & $55(28)$ & \\
\hline Moderate & $3(6)$ & $111(44)$ & $113(50)$ & \\
\hline Severe & $31(56)$ & $111(44)$ & $38(19)$ & \\
\hline Critical & $21(38)$ & $19(7)$ & $6(3)$ & \\
\hline $25 \mathrm{OH}$ vitamin $\mathrm{D}^{\mathrm{a}, \star}(\mathrm{ng} / \mathrm{ml})$ & $24 \pm 19$ & $30 \pm 22$ & $30 \pm 22$ & 0.047 \\
\hline Creatinine $^{\mathrm{a}}(\mathrm{mg} / \mathrm{dl})$ & $2 \pm 1$ & $1 \pm 1$ & $1 \pm 1$ & 0.007 \\
\hline Calcium $^{\mathrm{a}}$ (mg/dl) & $9 \pm 1$ & $9 \pm 1$ & $9 \pm 1$ & 0.001 \\
\hline Phosphora $^{\mathrm{a}}(\mathrm{mg} / \mathrm{dl})$ & $3 \pm 2$ & $3 \pm 1$ & $3 \pm 1$ & 0.25 \\
\hline $\operatorname{Albumin}^{\mathrm{a}}(\mathrm{g} / \mathrm{dl})$ & $3 \pm 1$ & $4 \pm 1$ & $4 \pm 1$ & 0.001 \\
\hline
\end{tabular}

Table 2. Demographic and medical characteristics of 508 cases of COVID-19 disease categorized by outcome. $D M$ diabetes mellitus, $H T N$ hypertension, $I H D$ ischemic heart disease, $B M I$ body mass index. ${ }^{2}$ Mean \pm SD.

*The P-value has been calculated after recategorized disease outcome to recovery and death groups.

60 years was five times higher than that of people 30 or younger. Mortality is inversely related to serum levels of $25(\mathrm{OH}) \mathrm{D}$, calcium, albumin, and renal function.

The cut-off points for $25(\mathrm{OH}) \mathrm{D}$ quartiles $(25,50$, and 75$)$ are 14,24 , and $37 \mathrm{ng} / \mathrm{ml}$, respectively. The ICU admission rate, and severity of disease and mortality decreased significantly across quartiles of $25(\mathrm{OH}) \mathrm{D}$. The relationships of demographic and medical parameters of participants, and disease severity and outcome across quartiles of serum $25(\mathrm{OH}) \mathrm{D}$ is shown in Table 3.

In the multivariate regression analysis, in-hospital mortality increases $4 \%$ by age, and decrease $3 \%, 47 \%$ and $79 \%$ by serum levels of $25(\mathrm{OH}) \mathrm{D}$, calcium, and albumin, respectively. Details were showed in Table 4 .

\section{Discussion}

In this cross-sectional study, 556 patients were studied. There was a negative correlation between disease severity and history of vitamin D supplementation, serum levels of $25(\mathrm{OH}) \mathrm{D}$, calcium, phosphorus, and albumin. Also, there was a negative correlation between in-hospital mortality and serum levels of $25(\mathrm{OH}) \mathrm{D}$ and calcium. The rate of admission to ICU, and disease severity and mortality rate decreased significantly across quartiles of 25(OH)D.

Age was both a risk factor for COVID-19 disease and its severity in this study. This finding is consistent with the findings of previous studies. For every 5 years of increase in patient age in the USA, the rate of hospitalization and mortality increase by $34 \%$ and $10-18 \%$, respectively ${ }^{23,24}$. The imbalance of the immune system and comorbidities intensifies the severity of the disease and consequently increases the mortality rate ${ }^{25}$.

In this study, there was no significant difference between gender and disease severity, and outcome. In a review article, the male-to-female ratio in patients admitted for COVID-19 was similar in three studies in France, Spain, and Switzerland. Male sex hormones, concurrent diseases, behavioral differences, and more exposure of men to pathogens may play a role in these differences ${ }^{26}$.

There was no relationship between comorbidities with the severity and outcome of COVID-19 disease in this study. Bajgain etal reported that there is no clear association between these comorbidities and mortality rate $^{27}$. But, these factors have been associated with increased severity and mortality of COVID-19 disease in some other studies ${ }^{28-30}$. This discrepancy may be due to different methods of study and participant demographic characteristics such as age and the male-to-female ratio. In our study, the diagnosis of comorbidities was based on medical history. We didn't have online access to the patient's previous medical records.

In this study, the number of patients admitted to ICU is 3.8 times and the in-hospital mortality rate is twice the globally national death rate in $\operatorname{Iran}^{31,32}$. This study was performed at the time of the first peak of the disease in Iran. At that time, the number of PCR tests performed to diagnose COVID-19 was low. Our hospital is a tertiary and referral center for respiratory diseases and COVID-19. Therefore, more serious patients refer to this center and one-fifth of our patients had over 70 years old. Of course, the in-hospital mortality rate in this study is lower than in other centers. About $32-40 \%$ of hospitalized patients need to be admitted to the ICU and their 


\begin{tabular}{|c|c|c|c|c|c|}
\hline & \multicolumn{4}{|c|}{ Serum $25(\mathrm{OH}) \mathrm{D}$ quartiles } & \multirow[b]{2}{*}{ P-value } \\
\hline & Q1 & Q2 & Q3 & Q4 & \\
\hline \multicolumn{6}{|l|}{ Admision ward ${ }^{\mathrm{a}}$} \\
\hline Non ICU & $95(78)$ & $105(85)$ & $106(90)$ & $114(95)$ & \multirow{2}{*}{$<0.0001^{*}$} \\
\hline ICU & $26(22)$ & $19(15)$ & $12(10)$ & 6(5) & \\
\hline \multicolumn{6}{|l|}{$\operatorname{Sex}^{\mathrm{a}}$} \\
\hline Male & $69(57)$ & $69(56)$ & $65(55)$ & $46(38)$ & \multirow{2}{*}{$0.005^{*}$} \\
\hline Female & $52(43)$ & $55(44)$ & $53(45)$ & $74(62)$ & \\
\hline \multicolumn{6}{|l|}{$\mathbf{D M}^{\mathrm{a}}$} \\
\hline No & $95(78)$ & $97(78)$ & $91(77)$ & 92(77) & \multirow{2}{*}{0.69} \\
\hline Yes & $26(22)$ & $27(22)$ & $27(23)$ & $28(23)$ & \\
\hline \multicolumn{6}{|l|}{ IHD } \\
\hline No & $103(85)$ & $108(87)$ & $102(86)$ & $103(86)$ & \multirow{2}{*}{$0.92^{*}$} \\
\hline Yes & $18(15)$ & $16(13)$ & $16(14)$ & $17(14)$ & \\
\hline \multicolumn{6}{|l|}{ 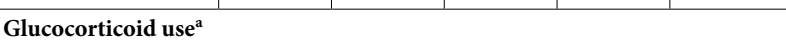 } \\
\hline No & $118(97)$ & $114(92)$ & $113(96)$ & $114(95)$ & \multirow{2}{*}{$0.68^{*}$} \\
\hline Yes & $3(3)$ & $10(8)$ & $5(4)$ & $6(5)$ & \\
\hline \multicolumn{6}{|c|}{ Vitamin D supplement use ${ }^{\mathrm{a}}$} \\
\hline No & $114(94)$ & $104(84)$ & $95(80)$ & $88(77)$ & \multirow{2}{*}{$<0.0001^{*}$} \\
\hline Yes & $7(6)$ & $20(16)$ & $23(20)$ & $32(23)$ & \\
\hline \multicolumn{6}{|c|}{ COVID-19 disease severity ${ }^{\mathrm{a}}$} \\
\hline Mild & $16(13)$ & $16(13)$ & $18(15)$ & $15(13)$ & \multirow{4}{*}{0.01} \\
\hline Moderate & $48(40)$ & $54(44)$ & $43(37)$ & $62(52)$ & \\
\hline Severe & $31(26)$ & $35(28)$ & $45(38)$ & $36(30)$ & \\
\hline Critical & $26(21)$ & $19(15)$ & $12(10)$ & $6(5)$ & \\
\hline \multicolumn{6}{|c|}{ COVID-19 disease outcome $\mathrm{e}^{\mathrm{a}}$} \\
\hline Death & $17(14)$ & $14(11)$ & $13(11)$ & $6(5)$ & \multirow{2}{*}{$0.03^{*}$} \\
\hline Recovery & $104(86)$ & $110(89)$ & $104(89)$ & $113(95)$ & \\
\hline Age $\left(\right.$ year) ${ }^{\mathrm{b}}$ & $54 \pm 18$ & $55 \pm 17$ & $56 \pm 17$ & $59 \pm 16$ & 0.17 \\
\hline $\mathrm{BMI}^{\mathrm{b}}$ & $27 \pm 4$ & $26 \pm 5$ & $28 \pm 5$ & $28 \pm 5$ & 0.09 \\
\hline Creatinin $(\mathrm{mg} / \mathrm{dl})^{\mathrm{b}}$ & $2 \pm 1$ & $2 \pm 1$ & $2 \pm 2$ & $1 \pm 0$ & 0.28 \\
\hline Cacium $(\mathrm{mg} / \mathrm{dl})^{\mathrm{b}}$ & $9 \pm 1$ & $9 \pm 1$ & $9 \pm 1$ & $9 \pm 1$ & 0.44 \\
\hline Phosphor $(\mathrm{mg} / \mathrm{dl})^{\mathrm{b}}$ & $3 \pm 2$ & $3 \pm 1$ & $3 \pm 1$ & $3 \pm 1$ & 0.50 \\
\hline $\operatorname{Albumin}(\mathrm{g} / \mathrm{dl})^{\mathrm{b}}$ & $3 \pm 1$ & $3 \pm 1$ & $4 \pm 1$ & $4 \pm 1$ & 0.05 \\
\hline
\end{tabular}

Table 3. The relationships of demographic and medical parameters across quartiles of serum 25(OH) D. DM diabetes mellitus, HTN hypertension, IHD ischemic heart disease, BMI body mass index. ${ }^{\mathrm{a}} \mathrm{n}(\%) .{ }^{\mathrm{b}} \mathrm{Mean} \pm \mathrm{SD}$. ${ }^{\star}$ Cochran-Armitage test for trend.

mortality rate is about $15-39 \%$ in other studies ${ }^{33,34}$. Experienced and well-trained personnel to care for patients with respiratory disorders and infectious diseases and access to adequate facilities for non-invasive and invasive ventilation can justify these results.

In the present study, $40 \%$ percent of patients had $25(\mathrm{OH}) \mathrm{D}$ less than $20 \mathrm{ng} / \mathrm{ml}$. Contrary to expectations, although Iran is a sunny country, vitamin D deficiency is common in all age groups. The reason is the lack of intake through food, reduced synthesis of this vitamin in the skin, and the type of clothing, and lack of widespread supplementation, which is common in some countries ${ }^{36-37}$.

In the present study, the patients with low blood levels of calcium, phosphorus, and albumin had more severe diseases, poor outcomes, and mortality. Similar results were found in other published articles. In one study, among patients with COVID-19, serum calcium levels were $0.8 \mathrm{mg} / \mathrm{dl}$ lower than in other patients ${ }^{38}$. Patients who died of COVID-19 had a serum albumin level of $4.6 \mathrm{~g} / \mathrm{l}$ lower than those who survived ${ }^{39}$. This relationship can be explained in several aspects. First, each of these nutrients have a special role in the function of the immune system and various parts of the body. Second, their deficiency of is an indirect index of the patient's nutritional status or concomitant conditions such as obesity, renal and liver failure, and diabetes. Third, hypocalcemia due to hypoalbuminemia may affect these results and it is better to correct the amount of serum calcium according to albumin level.

There was a negative correlation between disease severity and serum levels of $25(\mathrm{OH}) \mathrm{D}$ in this study. The mean level of 25(OH)D in patients admitted to the ICU was $11 \mathrm{ng} / \mathrm{ml}$ less than other groups. This finding has been shown in other studies. In the acute critically ill patients with COVID-19, the mean level of vitamin D was lower (14 vs. $28 \mathrm{ng} / \mathrm{ml})$, and the prevalence of vitamin D deficiency $(25(\mathrm{OH}) \mathrm{D}<20 \mathrm{ng} / \mathrm{dl}$ ) was higher than 


\begin{tabular}{|c|c|c|c|c|}
\hline \multirow[b]{3}{*}{ Independent variable } & \multicolumn{4}{|c|}{ Multivariate analysis } \\
\hline & \multirow[b]{2}{*}{ Odds ratio } & \multicolumn{2}{|c|}{ 95\% CI for $\operatorname{EXP}(B)$} & \multirow[b]{2}{*}{ P value } \\
\hline & & Lower & Upper & \\
\hline Age & 1.04 & 1.02 & 1.06 & $<0.001$ \\
\hline Sex (male) & 0.89 & 0.51 & 1.56 & 0.69 \\
\hline BMI & 0.97 & 0.92 & 1.03 & 0.35 \\
\hline $25 \mathrm{OH}$ vitamin $\mathrm{D}$ & 0.97 & 0.96 & 0.99 & 0.04 \\
\hline Diabetes mellitus & 1.05 & 0.54 & 2.02 & 0.89 \\
\hline Hypertension & 0.79 & 0.26 & 2.42 & 0.68 \\
\hline Ischemic heart disease & 0.68 & 0.28 & 1.62 & 0.38 \\
\hline Creatinine & 1.08 & 0.90 & 1.30 & 0.39 \\
\hline Calcium & 0.53 & 0.36 & 0.80 & 0.002 \\
\hline Phosphor & 1.13 & 0.90 & 1.43 & 0.29 \\
\hline Albumin & 0.21 & 0.11 & 0.38 & $<0.001$ \\
\hline
\end{tabular}

Table 4. Multivariate odds ratio and $95 \%$ confidence for association between the serum level of 25 hydroxyvitamin D and COVID-19 disease mortality. COVID-19 coronavirus 2019 disease, CI confidence interval, $B M I$ body mass index. Mortality vs. recovery. After adjustment for sex, BMI, past history of diabetes mellitus, hypertension, ischemic heart disease, creatinine, phosphor, albumin. Odds ratio change in mortality per standard deviation increase in scale independent variable. Each odds ratio result is adjusted for each of the other independent variables in the table.

asymptomatic patients(96 vs. 33\%). In patients with COVID-19 and concomitant vitamin D deficiency, and the mortality rate was 7 times ( 21 vs. $3 \%$ ) than those with sufficient vitamin $\mathrm{D}^{40}$.

In a cohort study by Baktash et al. ${ }^{41}$, the median level of $25(\mathrm{OH}) \mathrm{D}$ was lower inpatients with COVID-19 than healthy controls. This difference in $25(\mathrm{OH}) \mathrm{D}$ between the two groups was much greater than their study $(62 \mathrm{ng} / \mathrm{ml})$. Of course, they have compared patients with healthy people and their participants were older. Unlike previous studies, Jevalikar ${ }^{42}$ and Panagiotou ${ }^{43}$ did not find any relationship between $25(\mathrm{OH}) \mathrm{D}$ level and clinical parameters, inflammatory markers, or mortality rate in COVID-19 patients. The different results reported in these studies may be due to significant differences in the characteristics of participants and the presence of comorbidities. However, Panagiotou also found vitamin D deficiency was more common in patients admitted to the ICU. They treated patients with vitamin D supplements immediately after the diagnosis of vitamin D deficiency, which may have affected the course of the disease.

Vitamin D supplementation was associated with reduced disease severity and mortality in this study. In a few clinical trials, vitamin D administration has reduced the risk of COVID-19 disease, its morbidity, and mortality ${ }^{44-46}$. In a retrospective study, people with a history of a low mean level of $25(\mathrm{OH}) \mathrm{D}$ were more likely to develop COVID-19 disease than those with a higher level of $25(\mathrm{OH}) \mathrm{D}(11 \mathrm{vs} .25 \mathrm{ng} / \mathrm{ml} \text {, respectively })^{47}$. Although in another study, a high dose of vitamin D has did not affect on the course of COVID-19 disease, and comments on this subject need further investigations ${ }^{48}$.

In this study, age was directly related to mortality, but disease severity, serum levels of 25-hydroxyvitamin $\mathrm{D}$, creatinine, calcium, and albumin were inversely related to mortality due to COVID-19 disease.

There are pieces of evidence to suggest the link between 25(OH)D levels and COVID-19 disease. Vitamin D deficiency may increase the risk of COVID-19 disease and its severity and mortality. In a cohort study of 185 patients with COVID-19 within 66 days, 50\% were admitted, 28 required mechanical ventilation, and 16 died. When adjusted for age, gender, and comorbidities, $25(\mathrm{OH}) \mathrm{D}<12 \mathrm{ng} / \mathrm{ml}$ was associated with a higher risk of death (HR 14.73, 95\% CI 4.16-52.19, $\mathrm{P}<0.001)^{49}$. In a retrospective cohort study, the relative risk and predicted rate of COVID-19 disease was higher in patients with vitamin D deficiency than in those with sufficient vitamin $\mathrm{D}$ [1.77 and 1.8 times, respectively $)^{50}$. Vitamin D deficiency may also increase the risk of COVID-19 and disease severity and mortality. In a meta-analysis, a serum level of $25(\mathrm{OH}) \mathrm{D}<30 \mathrm{ng} / \mathrm{ml}$ increased the rate of hospital admissions and the mortality rate from COVID-19 (OR 1.82 for both) ${ }^{51}$. The mortality rates 10 days after admission in patients with COVID-19 disease and severe vitamin D deficiency $[25(\mathrm{OH}) \mathrm{D}<10] \mathrm{ng} / \mathrm{ml}$ was 10 times the other group $(25(\mathrm{OH}) \mathrm{D} \geq 10 \mathrm{ng} / \mathrm{ml})^{52}$.

Some studies did not find any relationship between the serum level of 25 -hydroxyvitamin $\mathrm{D}$ and the severity of COVID-19 disease and mortality. In a retrospective population-based study in Brazil, 14,692 people who recently measured serum levels of 25(OH)D and had RT-PCR test for COVID-19 were studied ${ }^{53}$. There was no significant difference between PCR positive and PCR negative individuals in mean $25(\mathrm{OH}) \mathrm{D}$ levels and the prevalence of vitamin D deficiency.

In a retrospective cohort study on 347 patients who hospitalised due to COVID-19 disease in Italy, similar results were obtained ${ }^{54}$.

In severe COVID-19 disease, the immune system does not have the proper response to prevent the multiplying and progressing virus infection. Instead, cytokine storms occur due to the release of excessive inflammatory factors $^{55}$. The relationship between Vitamin D and COVID-19 severity and outcome can be explained by different pathways and mechanisms, some of which we are mentioned here. Vitamin D has an antibacterial and antiviral property by regulating innate and adaptive cellular immunity, and physical barriers ${ }^{56}$. Vitamin $\mathrm{D}$ produces 
antimicrobial peptides (AMPs) such as cathelicidins and defensins by activating immune cells. A primary form of Cathelicidins (LL-37) inactivate viruses such as the Influenza A virus by destroying envelope proteins ${ }^{57}$. In the presence of a "cytokine storm" due to severe COVID-19 disease, inflammatory cytokines such as IL-6, IL-8, $\mathrm{CRP}$, and ferritin are released without the control of the immune system. Inflammatory cytokines damage the integrity of the lungs by causing inflammation, leading to pneumonia, which in turn causes a vicious cycle ${ }^{58}$. IL-6 increases the severity of COVID-19 by rearranging the angiotensin-converting enzyme (ACE2) receptors and inducing macrophage cathepsin L. Cathepsin L of macrophage cleaves the S1 subunit of the coronavirus spike glycoprotein. This is essential for the coronavirus to enter human host cells, a fusion of the endosome membrane of a host cell for virus, and the release of viral RNA ${ }^{59}$. Vitamin D can modulate the immune system and reduce the production of pro-inflammatory markers. Vitamin D supplementation has reduced interleukin-6 levels in several clinical trials ${ }^{60}$. Vitamin D may reduce the risk of ARDS and mortality from COVID-19 by raising ACE2 levels. The SARS-COV-2 virus binds to the ACE2 receptor expressed on the surface of lung epithelial cells and causes over-accumulation of angiotensin II by ACE2 downregulation. In the in-vivo studies, vitamin $\mathrm{D}$-binding protein has played a role in this interaction. Calcitriol, the active metabolite of vitamin $\mathrm{D}$, increases ACE2 expression in the lungs in animal studies. Vitamin D replacement may reduce lung damage by increasing ACE2 expression and synthesis of $\alpha$-1-antitrypsin by CD4+ T cells. $\alpha$-1-Antitrypsin is critical for lung integrity and repair and is required for the further production of anti-inflammatory interleukins such as IL-10. Vitamin $\mathrm{D}$ improves endothelial dysfunction by reducing the oxidative stress of free oxygen radicals, TNF-alpha and interleukin- 6 and suppressing the NF- $\mathrm{B}$ pathway. Endothelial dysfunction causes vascular inflammation and increased blood coagulation, which is seen in severe COVID-19. Vitamin D reduces the lung damage due to COVID-19 by stimulating the proliferation and migration of alveolar epithelial cells type II and reducing their apoptosis. It also inhibits the mesenchymal transition of an epithelial cell induced by TGF- $\beta$. In COVID-19, the function of type II pneumocytes is impaired, and the surfactant concentration decreases at the alveolar surface, and the alveoli are collapsed. In some studies, $1 \alpha, 25(\mathrm{OH}) 2 \mathrm{D}$ have caused an increase in surfactant and maybe prevent lung alveoli collapse $\mathrm{e}^{62-63}$. Studies have shown that acute inflammatory disease can decrease serum levels of $25(\mathrm{OH}) \mathrm{D}$. These changes were temporary and short-lived and resolved within $24-48 \mathrm{~h}$. There is a significant diurnal and seasonal fluctuation $(20 \%)$ in the serum level of $25(\mathrm{OH}) \mathrm{D}$ in each person during the day and its maximum amount is observed in the middle of the day and the summer and autumn. Due to this daily fluctuation, the sampling time makes a significant error in assessing the serum level of $25(\mathrm{OH}) \mathrm{D}^{65-67}$. Therefore, the timing of blood sampling from patients from the onset of symptoms and disease or blood drawing time can change the results. Although all participants entered this study in May and June, and fasting sampling was performed in the morning of the first day after admission.

This study had some limitations. First, vitamin D-binding protein was not measured, and since the amount of this protein decreases in many severe diseases, the potential impact of this reduction must be considered. Second, vitamin D levels were measured once, and if measured several times in the course of the disease we might be able to better answer its relationship to the severity and outcome of the disease. Third, Vitamin D levels are measured during May and June. Vitamin D levels are lower during the winter and spring than the summer and autumn ${ }^{68}$. The timing of the study may affect the results obtained in this study. Fourth, This study is a single-center study and all participants are Caucasians who live in the urban area. As a result, it may have high internal validity and low external validity. In any case, a cross-sectional study with this style can not examine the causal relationship between variables and we did not intend to conclude the cause-and-effect relationship between vitamin D and the severity of COVID-19.

However, judgments based on these limited studies are not logical. Most of these studies are observational, single-center, retrospective and with inadequate sample size. There are limited human or financial resources and a lack of enough time due to the COVID-19 disease pandemic. So, acceleration in the research project design and implementation, data collection and analysis, and publishing research results also affect the quality of articles. We suggest multinational, multicenter, double-blind randomized clinical trials or cohort studies clarify the issue.

\section{Conclusion}

This study evaluated the association between 25(OH)D levels and the severity and outcome of patients with COVID-19 admitted to the hospital. The disease was severe or critical in $44 \%$ of admitted cases and $13 \%$ of them admitted to ICU. The mortality rate was $10.8 \%$. Old age, vitamin D deficiency, hypocalcemia, hypophosphatemia, hypoalbuminemia, and renal failure are associated with disease severity and admission to ICU. Old age, disease severity, low serum level of $25(\mathrm{OH}) \mathrm{D}$, hypocalcemia, hypoalbuminemia, and renal failure were associated with a higher mortality rate.

\section{Data availability}

All authors have had online access to patients' records and data during the study.

Received: 5 January 2021; Accepted: 10 August 2021

Published online: 02 September 2021

\section{References}

1. World Health Organization. WHO Director-General's Opening Remarks at the World Health Assembly-9 November 2020 (WHO, 2020).

2. World Health Organization. Rolling Updates on Coronavirus Disease (COVID-19) (WHO, 2020).

3. World Health Organization. Weekly Epidemiological Update-3 November 2020 (WHO, 2020). 
4. Wu, Z. \& McGoogan, J. M. Characteristics of and important lessons from the coronavirus disease 2019 (COVID-19) outbreak in China summary of a report of 72,314 cases from the Chinese center for disease control and prevention. JAMA. https://doi.org/10. 1001/jama.2020.2648 (2020).

5. Wang, D. et al. Clinical characteristics of 138 hospitalized patients with 2019 novel coronavirus-infected pneumonia in Wuhan, China. JAMA. 323(11), 1061-1069. https://doi.org/10.1001/jama.2020.1585 (2020).

6. Chen, T. et al. Clinical characteristics of 113 deceased patients with coronavirus disease 2019: Retrospective study. BMJ 368, m1091. https://doi.org/10.1136/bmj.m1091 (2020).

7. World Health Organization. Coronavirus Disease (COVID-19) Pandemic, Coronavirus Disease (COVID-19) Outbreak Situation (WHO, 2020).

8. Onder, G., Rezza, G. \& Brusaferro, S. Case-fatality rate and characteristics of patients dying in relation to COVID-19 in Italy. JAMA. https://doi.org/10.1001/jama.2020.4683 (2020).

9. Shim, E., Tariq, A., Choi, W., Lee, Y. \& Chowell, G. Transmission potential and severity of COVID-19 in South Korea. Int. J. Infect. Dis. https://doi.org/10.1016/j.ijid.2020.03.031 (2020).

10. Yuen, K. S., Ye, Z. W., Fung, S. Y., Chan, C. P. \& Jin, D. Y. SARS-CoV-2 and COVID-19: The most important research questions. Cell Biosci. 10, 40. https://doi.org/10.1186/s13578-020-00404-4 (2020).

11. Griffin, G. et al. Vitamin D and COVID-19: Evidence and recommendations for supplementation. R. Soc. Open Sci. 7(12), 201912. https://doi.org/10.1098/rsos.201912 (2020).

12. Grant, W. B. et al. Evidence that vitamin D supplementation could reduce risk of influenza and COVID-19 infections and deaths. Nutrients 12(4), E988. https://doi.org/10.3390/nu12040988 (2020).

13. McCartney, D. M. \& Byrne, D. G. Optimization of vitamin D status for enhanced immuno-protection against COVID-19. Iran. Med. J. 113(4), 58 (2020).

14. Tabrizi, R. et al. High prevalence of vitamin D deficiency among iranian population: A systematic review and meta-analysis. Iran. J. Med. Sci. 43(2), 125-139 (2018).

15. https://www.siemens-healthineers.com/en-us/laboratory-diagnostics/assays-by-diseases-conditions/bone-metabolism-assaysglobal/vitamin-d-total-assay. Accessed 5 Jan 2021.

16. Bakhshayeshkaram, M., Haseli, S. \& Iranpour, P. Radiological mimickers of COVID-19 pneumonia: A pictorial review. Tanaffos 19(2), 100-107 (2020).

17. Mamani, M., Muceli, N., Ghasemi Basir, H. R., Vasheghani, M. \& Poorolajal, J. Association between serum concentration of 25-hydroxyvitamin D and community-acquired pneumonia: A case-control study. Int. J. Gen. Med. 10, 423-429. https://doi.org/ 10.2147/IJGM.S149049 (2017).

18. Holick, M. F. The vitamin D deficiency pandemic: Approaches for diagnosis, treatment and prevention. Rev. Endocr. Metab. Disord. 18(2), 153-165. https://doi.org/10.1007/s11154-017-9424-1 (2017).

19. Giustina, A. et al. Consensus statement from 2nd international conference on controversies in vitamin D. Rev. Endocr. Metab. Disord. 21(1), 89-116. https://doi.org/10.1007/s11154-019-09532-w (2020).

20. Araki, T. et al. Vitamin D intoxication with severe hypercalcemia due to manufacturing and labeling errors of two dietary supplements made in the United States. J. Clin. Endocrinol. Metab. 96(12), 3603-3608. https://doi.org/10.1210/jc.2011-1443 (2011).

21. World Health Organization. Clinical Management of COVID-19. Interim Guidance. COVID-19: Clinical care. WHO/Publications/ Overview/Clinical management of COVID-19. WHO Reference Number: WHO/2019-nCoV/clinical/2020.5 (2020). https://www. who.int/publications/i/item/clinical-management-of-COVID-19. Accessed 5 Jan 2021.

22. Kabootari, M., Akbarpour, S., Azizi, F. \& Hadaegh, F. Sex specific impact of different obesity phenotypes on the risk of incident hypertension: Tehran lipid and glucose study. Nutr. Metab. (Lond.). 16, 16. https://doi.org/10.1186/s12986-019-0340-0 (2019).

23. Price-Haywood, E. G., Burton, J., Fort, D. \& Seoane, L. Hospitalization and mortality among black patients and white patients with COVID-19. N. Engl. J. Med. 382(26), 2534-2543. https://doi.org/10.1056/NEJMsa2011686 (2020).

24. Zheng, Z. et al. Risk factors of critical \& mortal COVID-19 cases: A systematic literature review and meta-analysis. J. Infect. 81(2), e16-e25. https://doi.org/10.1016/j.jinf.2020.04.021 (2020).

25. Blagosklonny, M. V. From causes of aging to death from COVID-19. Aging (Albany NY). 12(11), 10004-10021. https://doi.org/10. 18632/aging.103493 (2020).

26. Gebhard, C., Regitz-Zagrosek, V., Neuhauser, H. K., Morgan, R. \& Klein, S. L. Impact of sex and gender on COVID-19 outcomes in Europe. Biol. Sex Differ. 11(1), 29. https://doi.org/10.1186/s13293-020-00304-9 (2020).

27. Bajgain, K. T., Badal, S., Bajgain, B. B. \& Santana, M. J. Prevalence of comorbidities among individuals with COVID-19: A rapid review of current literature. Am. J. Infect. Control. 49(2), 238-246. https://doi.org/10.1016/j.ajic.2020.06.213 (2021).

28. Yang, J. et al. Prevalence of comorbidities and its effects in patients infected with SARS-CoV-2: A systematic review and metaanalysis. Int. J. Infect. Dis. 94, 91-95. https://doi.org/10.1016/j.ijid.2020.03.017 (2020).

29. Wendel Garcia, P. D. et al. Prognostic factors associated with mortality risk and disease progression in 639 critically ill patients with COVID-19 in Europe: Initial report of the international RISC-19-ICU prospective observational cohort. EClinicalMedicine. https://doi.org/10.1016/j.eclinm.2020.100449 (2020).

30. Richardson, S., et al. Presenting characteristics, comorbidities, and outcomes among 5700 patients hospitalized with COVID-19 in the New York City area. JAMA 323(20), 2052-2059 (2020). https://doi.org/10.1001/jama.2020.6775. Erratum in: JAMA 323(20), $2098(2020)$.

31. https://www.who.int/emergencies/diseases/novel-coronavirus-2019/situation-reports. Accessed 5 Jan 2021.

32. The Ministry of Health of Iran. Identification of 13843 New Patients with Covid 19 in the Country/5832 Patients are Admitted to the Intensive Care Unit, Number 217880. https://behdasht.gov.ir/news/NEWS. Accessed 5 Jan 2021.

33. Wiersinga, W. J., Rhodes, A., Cheng, A. C., Peacock, S. J. \& Prescott, H. C. Pathophysiology, transmission, diagnosis, and treatment of coronavirus disease 2019 (COVID-19): A review. JAMA 324(8), 782-793. https://doi.org/10.1001/jama.2020.12839 (2020).

34. Abate, S. M., Ahmed Ali, S., Mantfardo, B. \& Basu, B. Rate of intensive care unit admission and outcomes among patients with coronavirus: A systematic review and Meta-analysis. PLoS ONE 15(7), e0235653. https://doi.org/10.1371/journal.pone.0235653 (2020).

35. van Schoor, N. \& Lips, P. Global overview of vitamin D status. Endocrinol. Metab. Clin. N. Am. 46(4), 845-870. https://doi.org/10. 1016/j.ecl.2017.07.002 (2017).

36. Vatandost, S. et al. Prevalence of vitamin D deficiency in Iran: A systematic review and meta-analysis. Nutr. Health 24(4), 269-278. https://doi.org/10.1177/0260106018802968 (2018).

37. Ejtahed, H. S., Shab-Bidar, S., Hosseinpanah, F., Mirmiran, P. \& Azizi, F. Estimation of vitamin D intake based on a scenario for fortification of dairy products with vitamin D in a tehranian population. Iran. J. Am. Coll. Nutr. 35(5), 383-391. https://doi.org/ 10.1080/07315724.2015.1022269 (2016).

38. Sun, J. K. et al. Serum calcium as a biomarker of clinical severity and prognosis in patients with coronavirus disease 2019. Aging (Albany NY). 12(12), 11287-11295. https://doi.org/10.18632/aging.103526 (2020).

39. Huang, J. et al. Hypoalbuminemia predicts the outcome of COVID-19 independent of age and co-morbidity. J. Med. Virol. https:// doi.org/10.1002/jmv.26003 (2020).

40. Jain, A. et al. Analysis of vitamin D level among asymptomatic and critically ill COVID-19 patients and its correlation with inflammatory markers. Sci. Rep. 10(1), 20191. https://doi.org/10.1038/s41598-020-77093-z (2020). 
41. Baktash, V. et al. Vitamin D status and outcomes for hospitalised older patients with COVID-19. Postgrad. Med. J. https://doi.org/ 10.1136/postgradmedj-2020-138712 (2020).

42. Jevalikar, G. et al. Lack of association of baseline 25 -hydroxyvitamin D levels with disease severity and mortality in Indian patients hospitalized for COVID-19. Sci Rep. 11(1), 6258. https://doi.org/10.1038/s41598-021-85809-y (2021).

43. Panagiotou, G. et al. Low serum 25-hydroxyvitamin D (25[OH]D) levels in patients hospitalized with COVID-19 are associated with greater disease severity. Clin. Endocrinol. (Oxf.). https://doi.org/10.1111/cen.14276 (2020).

44. Entrenas Castillo, M. et al. Effect of calcifediol treatment and best available therapy versus best available therapy on intensive care unit admission and mortality among patients hospitalized for COVID-19: A pilot randomized clinical study. J. Steroid Biochem. Mol. Biol. 203, 105751. https://doi.org/10.1016/j.jsbmb.2020.105751 (2020).

45. Ling, S. F. et al. High-dose cholecalciferol booster therapy is associated with a reduced risk of mortality in patients with COVID19: A cross-sectional multi-centre observational study. Nutrients 12(12), 3799. https://doi.org/10.3390/nu12123799 (2020).

46. Annweiler, G. et al. Vitamin D supplementation associated to better survival in hospitalized frail elderly COVID-19 patients: The GERIA-COVID quasi-experimental study. Nutrients 12(11), 3377. https://doi.org/10.3390/nu12113377 (2020).

47. D’Avolio, A. et al. 25-Hydroxyvitamin D concentrations are lower in patients with positive PCR for SARS-CoV-2. Nutrients 12(5), 1359. https://doi.org/10.3390/nu12051359 (2020).

48. Cereda, E. et al. Vitamin D supplementation and outcomes in coronavirus disease 2019 (COVID-19) patients from the outbreak area of Lombardy, Italy. Nutrition 82, 111055. https://doi.org/10.1016/j.nut.2020.111055 (2020).

49. Radujkovic, A. et al. Vitamin D deficiency and outcome of COVID-19 patients. Nutrients 12(9), 2757. https://doi.org/10.3390/ nu12092757 (2020).

50. Meltzer, D. O. et al. Association of vitamin D status and other clinical characteristics with COVID-19 test results. JAMA Netw. Open 3(9), e2019722. https://doi.org/10.1001/jamanetworkopen.2020.19722 (2020).

51. Pereira, M., Dantas Damascena, A., Galvão Azevedo, L. M., de Almeida, O. T. \& da Mota, S. J. Vitamin D deficiency aggravates COVID-19: Systematic review and meta-analysis. Crit. Rev. Food Sci. Nutr. https://doi.org/10.1080/10408398.2020.1841090 (2020).

52. Carpagnano, G. E. et al. Vitamin D deficiency as a predictor of poor prognosis in patients with acute respiratory failure due to COVID-19. J. Endocrinol. Investig. 44(4), 765-771. https://doi.org/10.1007/s40618-020-01370-x (2021).

53. Brandão, C. M. Á. et al. No association between vitamin D status and COVID-19 infection in São Paulo Brazil. Arch. Endocrinol. Metab. https://doi.org/10.20945/2359-3997000000343 (2021).

54. Ferrari, D. \& Locatelli, M. No significant association between vitamin D and COVID-19. A retrospective study from a northern Italian hospital. Int. J. Vitam. Nutr. Res. https://doi.org/10.1024/0300-9831/a000687 (2020).

55. Adams, K. K. \& Baker, W. L. Sobieraj DM myth busters: Dietary supplements and COVID-19. Ann. Pharmacother. 54(8), 820-826. https://doi.org/10.1177/1060028020928052 (2020).

56. Mahmoudi, S., Rezaei, M., Mansouri, N., Marjani, M. \& Mansouri, D. Immunologic features in coronavirus disease 2019: Functional exhaustion of T cells and cytokine storm. J. Clin. Immunol. 40(7), 974-976. https://doi.org/10.1007/s10875-020-00824-4 (2020).

57. Ali, N. Role of vitamin D in preventing of COVID-19 infection, progression and severity. J Infect Public Health. https://doi.org/ 10.1016/j.jiph.2020.06.021 (2020).

58. Beard, J. A., Bearden, A. \& Striker, R. Vitamin D and the anti-viral state. J. Clin. Virol. 50(3), 194-200. https://doi.org/10.1016/j. jcv.2010.12.00 (2011).

59. Ebadi, M. \& Montano-Loza, A. J. Perspective: Improving vitamin D status in the management of COVID-19. Eur. J. Clin. Nutr. 74(6), 856-859. https://doi.org/10.1038/s41430-020-0661-0 (2020).

60. Wong, N. A. \& Saier, M. H. Jr. The SARS-coronavirus infection cycle: A survey of viral membrane proteins, their functional interactions and pathogenesis. Int. J. Mol. Sci. 22(3), 1308. https://doi.org/10.3390/ijms22031308 (2021).

61. Greiller, C. L. \& Martineau, A. R. Modulation of the immune response to respiratory viruses by vitamin D. Nutrients 7(6), 4240-4270. https://doi.org/10.3390/nu7064240 (2015).

62. Miroliaee, A. E., Salamzadeh, J., Shokouhi, S. \& Sahraei, Z. The study of vitamin D administration effect on CRP and Interleukin-6 as prognostic biomarkers of ventilator associated pneumonia. J. Crit. Care 44, 300-305. https://doi.org/10.1016/j.jcrc.2017.08.040 (2018).

63. Kim, D. H., Meza, C. A., Clarke, H., Kim, J. S. \& Hickner, R. C. Vitamin D and endothelial function. Nutrients 12(2), 575. https:// doi.org/10.3390/nu12020575 (2020).

64. Zheng, S. et al. Vitamin D attenuates lung injury via stimulating epithelial repair, reducing epithelial cell apoptosis and inhibits TGF- $\beta$ induced epithelial to mesenchymal transition. Biochem. Pharmacol. 177, 113955. https://doi.org/10.1016/j.bcp.2020.113955 (2020).

65. Bassatne, A. et al. The link between COVID-19 and VItamin D (VIVID): A systematic review and meta-analysis. Metabolism. https://doi.org/10.1016/j.metabol.2021.154753 (2021).

66. Smolders, J., van den Ouweland, J., Geven, C., Pickkers, P. \& Kox, M. Letter to the Editor: Vitamin D deficiency in COVID-19: Mixing up cause and consequence. Metabolism 115, 154434. https://doi.org/10.1016/j.metabol.2020.154434 (2021).

67. French, C. B., McDonnell, S. L. \& Vieth, R. 25-Hydroxyvitamin D variability within-person due to diurnal rhythm and illness: A case report. J. Med. Case Rep. 13(1), 29. https://doi.org/10.1186/s13256-018-1948-9 (2019).

68. Malacova, E. et al. Prevalence and predictors of vitamin D deficiency in a nationally representative sample of adults participating in the 2011-2013 Australian Health Survey. Br. J. Nutr. 121(8), 894-904. https://doi.org/10.1017/S0007114519000151 (2019).

\section{Acknowledgements}

The authors dedicate this article to physicians, nurses, and medical personnel who have sacrificed their lives to care for patients with COVID-19. The authors thank Batoul Khoundabi (Assistant Professor of Biostatistics, Iran-Helal Institute of Applied Science and Technology) for re-analyzing the data.

\section{Author contributions}

M.V. designed and worked in all steps of project. She wrote the manuscript and reviewed it. She revised and edited the article in all steps; N.J. collected data; P.B. Analyzed data; MR: had done laboratory tests. She reviewed and edited manuscript. R.A.: Analyzed data, corrected manuscript after revision. M.M.: supervised investigation and edited the manuscript.

\section{Funding}

The authors do not receive any funding for this study.

\section{Competing interests}

The authors declare no competing interests. 


\section{Additional information}

Correspondence and requests for materials should be addressed to M.R.

Reprints and permissions information is available at www.nature.com/reprints.

Publisher's note Springer Nature remains neutral with regard to jurisdictional claims in published maps and institutional affiliations.

(c) (1) Open Access This article is licensed under a Creative Commons Attribution 4.0 International License, which permits use, sharing, adaptation, distribution and reproduction in any medium or format, as long as you give appropriate credit to the original author(s) and the source, provide a link to the Creative Commons licence, and indicate if changes were made. The images or other third party material in this article are included in the article's Creative Commons licence, unless indicated otherwise in a credit line to the material. If material is not included in the article's Creative Commons licence and your intended use is not permitted by statutory regulation or exceeds the permitted use, you will need to obtain permission directly from the copyright holder. To view a copy of this licence, visit http://creativecommons.org/licenses/by/4.0/.

(C) The Author(s) 2021 